\title{
FUNDAMENTAL STUDIES OF SEPARATION PROCESSES
}

\section{MASTER}

L. B. Rogers

Department of Chemistry

University of Georgia

Athens, Georgia 30602
- NOTICE an account of work This report was prepared as an avernment. Neither the United States nor the Unitration, nor any of Research and Development Ad of their contractors, their employees, nor any employees, makes any subcontractors, or implied, or assumes any legal warranty. expass ibility for the accuracy, completuet or liability or res of any information, apparatus, produld no or usess disclosed, or represents thal its use wold not process disclosed, or red rights.
infringe privately owned

September 1977

PREPARED FOR THE

U. S. ENERGY RESEARCH AND DEVELOPMENT ADMINISTRATION UNDER CONTRACT EY-76-S-09-0854 


\section{DISCLAIMER}

This report was prepared as an account of work sponsored by an agency of the United States Government. Neither the United States Government nor any agency Thereof, nor any of their employees, makes any warranty, express or implied, or assumes any legal liability or responsibility for the accuracy, completeness, or usefulness of any information, apparatus, product, or process disclosed, or represents that its use would not infringe privately owned rights. Reference herein to any specific commercial product, process, or service by trade name, trademark, manufacturer, or otherwise does not necessarily constitute or imply its endorsement, recommendation, or favoring by the United States Government or any agency thereof. The views and opinions of authors expressed herein do not necessarily state or reflect those of the United States Government or any agency thereof. 


\section{DISCLAIMER}

Portions of this document may be illegible in electronic image products. Images are produced from the best available original document. 


\title{
TECHNICAL PROGRESS REPORT ON FUNDAMENTAL STUDIES OF SEPARATION PROCESSES
}

\author{
L. B. Rogers
}

\begin{abstract}
Studies completed during the past year were: pressure and temperature effects on retention behavior of ion pairs, fractionation studies of sulfur isotopes in carbon disulfide, anomolous peak shapes obtained in gas chromatography using liquid crystal stationary phases in an electrostatic field, and the application of a new steric-exclusion packing for molecular-weight fractionation of petroleum crudes. Studies are continuing on the effects of the dead volume of a detector on the peak shape as a function of flow rate and molecular weight of the solute and on basic studies relating to the optimization of chromatographic parameters in supercritical fluid chromatography of large molecules, especially polymers. New studies that have been initiated include: the fractionation and identification of vanadium species in crude oils, the study of recycling chromatography at elevated pressures for difficult separations such as those involving isotopes, and the application of gradient techniques in liquid chromatography for the fractionation of polymers. Finally, equipment has been ordered for making solubility studies relating to the precipitation of compounds from geothermal brines, but experiments have not yet begun.
\end{abstract}

"This report was prepared as an account of work sponsored by the United States Government. Neither the United States nor the United States Energy Research and Development Administration, nor any of their employees, nor any of their contractors, subcontractors, or their employees, makes any warranty, express or implied, or assumes any legal liability or responsibility for the accuracy, completeness or usefulness of any information, apparatus, product or process disclosed, or represents that its use would not infringe privately-owned rights." 


\section{INTRODUCTION}

It is three years since the Principal Investigator (PI) moved to the University of Georgia from Purdue University. Fortunately, the unusual series of serious breakdowns of major equipment, which were expensive both in time lost and in cost of repairs, tapered off to a normal level approximately one year ago. As a result, progress on research has been excellent as has the morale of the individuals within the group.

Two additional positive factors deserve mention. First, one graduate student doing ERDA-sponsored research received a large departmental fellowship sponsored by a nationally known chemical corporation while another received a smaller, but substantial, fellowship sponsored by the University. Second, two visiting faculty. members contributed greatly to the atmosphere and to the research accomplishments. Professor J. A. Lubkowitz of the Institute of Scientific Research, Caracas, Venezuela and Professor J. F. Parcher of the University of Mississippi each spent approximately half of their time doing research on topics within the scope of this contract.

In addition to the research accomplishments indicated in the abstract, up-dating of equipment has continued with the long-term goal of adding one or two more instruments each year to the list of those controlled by our on-line computer system. In addition; the transducers and controllers for temperature and pressure have been replaced so as to improve substantially the accuracy and precision of the data obtained from some of the equipment that was already on-line. The chief problem encountered during the past year has been the slow delivery of new and replacement parts, regardless of whether they were major items or small electrical components. For example, delivery of a special pressure gauge for the brine study described below required more than six months. As a result, the visiting faculty member, who had originally planned to work on that problem, never got started. (The gauge arrived less than a month before his departure from the laboratory.) Less spectacular examples were repeatedly encountered in our orders for 
small electronic components. We now spend additional time and money trying to locate the items by telephone before placing an order.

The results for different research topics have been discussed in the same order as in last year's Proposal. Some have been completed while others have just been started by first-year graduate students.

\section{RESULTS}

\section{Peak Shapes}

Liquid crystals. The goal of this study was to explore the generality of an unusual effect observed when a liquid crystal, used as a stationary phase in gas chromatography, was oriented by means of an electrostatic field. In a recent publication, we had shown that an electrostatic field across a layer of cholesteryl myristate not only produced a narrower chromatographic peak for a volatile solute such as acetone but, in addition, produced a small "knee" in the leading edge of the peak (1).

During the past year, this phenomenon has been studied in more detail, and a report has been issued (SRO-854-16). First, we have found by using other cholesteryl derlvatives that the myristate derivative is not unique in its behavior. Second, the phenomenon has been found to be somewhat different depending upon the inert carrier gas used. Furthermore, the knee was also accompanied, above 500 volts, by a decrease in the overall peak area and an increase in the baseline. By adding traces of methane to the helium, both changes could be decreased. Although hard evidence concerning the exact mechanism is missing, the presence of methane appears to be interfering with the reaction much as "quench" gases do in Geiger-Mueller and other counters. While it would be tempting to explain the phenomena in terms of decomposition of the volatile solute, the fact that an increase in baseline can be found in the absence of a volatile solute suggests that decomposition of the liquid crystal itself must occur. 
Although the same behavior was found for two other cholesteryl liquid crystals, the study was stopped because the phenomenon was not a broad, fundamental aspect of separation behavior.

Peak width and tailing. Excellent progress has been made in this basic study which is providing information that should be widely applicable for analyzing chromatographic peak shapes in terms of fundamental parameters. In brief, chromatographic peaks are usually assumed to be Gaussian regardless of how badly they may be tailed. The conventional practice is to calculate the number of theoretical plates from a measurement of peak width at half-height and from the retention time of the maximum in order to estimate the efficiency of the chromatographic column.

It is well known that actual peaks are distorted by a number of factors including dead volume arising from the detector itself or from the connecting tubing so that the original Gaussian is convoluted with one or more exponential factors. Unfortunately, in calculating higher statistical moments of a peak, the uncertainties in the results become unmanageable ( 25 to $50 \%$ uncertainty) as a result of noise in the original data. In essence, the new technique involves the use of areas rather than individual points so that much of the noise is averaged out (2).

In a study that is nearing completion, three commercially available detectors (two ultraviolet monitors and one refractive index monitor) have been compared using three different molecular weights of monodisperse polystyrenes. The detector systems had different dead volumes not only in the cells themselves but also in the connecting tubings. As expected, the dead volume in the detector proved to be the major contributor while the capillary connecting tubing made only a minor contribution. In addition, contrary to our earlier results when studying gas chromatography (2), empty tubing before the analytical column did not appear to distort the peaks as seriously as did empty tubing after the column. This may reflect the fact that the sample in 
liquid chromatography does not expand to fill all of the empty space before entering the column. In any case, if the observation can be confirmed when using a variety of solutes at different flow rates, it will change the approach to the problem of minimizing dead volume in liquid chromatography.

Future studies will be directed toward the study of dead-volume effects in more detail, particularly those related to the extra-column effects. In addition, simulation studies will be made to determine if two different exponential factors can be isolated by modifying the calculation procedure. At the present time, the contributions of two or more sources of tailing are confounded and treated as a single source. While it would be desirable to be able to deconvolute two or more contributions, we are not optimistic about being able to do so using our present calculation methods. For that reason, other approaches are also being explored.

\section{Chromatographic Fractionation of Sulfur Isotopes}

In an earlier study (3), we successfully examined the isotopic fractionations of carbon and oxygen in carbon dioxide by using short chromatographic columns plus a quadrupole mass spectrometer to follow molecules containing $\mathrm{C}-13$ and $\mathrm{O}-18$ using, respectively, masses 45 and 46 . In the present study of carbon disulfide, we had a more limited goal because $\mathrm{C}-13$ and $\mathrm{S}-33$ both produced the same nominal molecular mass. Furthermore, only a very small separation of sulfur isotopes 32 and 34 , an alpha of 1.0001, had been observed in distillation (4). Nevertheless, it was hoped that differences in adsorption would greatly amplify the isotopic differences.

Using silica columns, an average separation factor (alpha) of 1.0008 for ${ }^{32} \mathrm{~S} /{ }^{34} \mathrm{~S}$ was observed while on graphitized carbon the value was approximately 1.0005. In spite of the fact that individual values always fell on the same side of unity, the precision limits were very wide because the limit of reproducibility for the equipment 
was 3 to 5 parts in ten thousand for a series of approximately 6 replicates. Hence, the observed values for the separation factors differed from unity only by an amount approximately equal to the average standard deviation for the measurements.

Attempts to use other column packings and to change the pretreatment of the packings all proved to be unsuccessful. As a result, chromatographic fractionation would not be a viable approach for isotope fractionation using any of the systems we explored, so no further work is planned on the carbon disulfide system.

High-Temperature, High-Pressure Chromatography

Supercritical fluid chromatography. The use of supercritical fluids as mobile phases in chromatography became very popular, starting about ten years ago, because they appeared to offer the speed and resolution of gas chromatography for relatively non-volatile solutes that had previously been handled by liquid chromatography. During the intervening time, column packings for liquid chromatography have been greatly improved, and the separation speed has been increased by resorting to higher pressures. As a result, work with supercritical fluids has diminished just as rapidly as it once grew. However, Jentoft and Gouw (5) showed in 1970 that a series of oligomers of polystyrene could be fractionated with remarkably better resolution and in a much shorter time using supercritical pentane. For that reason, we investigated a sample of a polymeric methylphenylsilicone (6) and were able to demonstrate that two different series of oligomers were present. While spectacular results were obtained for that system, evidence was found that the effects of column length and particle size were not as simple to anticipate as expected. For that reason, a study of some of the fundamental variables using samples of monodisperse polystyrene was begun.

For the first few months of this study, other sources of irreproducibility were encountered. For example, impurities in the pentane carrier fluid resulted in gradual 
changes in retention behavior over a period of time. Originally, it was thought that the impurities could be removed by pretreatment with concentrated sulfuric acid followed by distillation, but the silica continued to be discolored after much use. At the present time, the pentane is pretreated with a mixture of silica and alumina followed by distillation. The presence of alumina, the result of a recent modification, appears to remove the last visible impurity.

After other variables had been eliminated, it became clear that much closer control of the pressure was needed, especially during refill strokes of the pump for the pentane. As a result, better controllers and more sensitive transducers were installed, and they have led to a significant improvement in performance.

Finally, there is now evidence that part of the polystyrene is strongly adsorbed by the silica packing and acts as a partitioning phase for the remainder of the polystyrene sample. The adsorbed layer then elutes near the end of the chromatogram in a large unresolved hump. By running chromatograms under comparable conditions using derivitized silica packings, both $\mathrm{C}_{18}$-bonded and phenyl-bonded materials, the shape, magnitude, and location of the unresolved hump has been changed. Hence, much of the unresolved envelope can be accounted for by strong adsorption of part of the sample.

Near the end of the present report, further information about the problem will be mentioned in discussing liquid chromatographic fractionations. Together, the two types of studies have served as cross-checks on one another. In addition, variables involved in the fractionation of polystyrene oligomers and in supercritical fluid chromatography itself are now much better understood. The supercritical work is currently being written up for publication.

Two years ago, we first attempted separations of oligomers using non-linear pressure programs. Although the mobility of heavy oligomers appeared to be related to density of the mobile phase, its density does not change in a linear fashion with pressure in a 
region of temperature just above a critical point. By using a simple non-linear pressure program involving two rates of change, much better resolutions of the heavier oligomers were observed. More complex changes will be performed under computer control in the future.

The application of supercritical fluid chromatography (as well as high-resolution liquid chromatography and gas chromatography) to the fractionation of vanadium chelates in crude oil has recently been started. It has long been known that volatile vanadium species occur that are predominately porphyrin chelates. It is also known that two different classes of porphyrins usually dominate the mixture: etioporphyrins and phylloporphyrins (7). Up to the present time, only mixtures of classes and of homologs within a given class have been reported. However, if we are successful in isolating individual species, it should be possible to identify each one by using mass spectrometry (8) infrared, and ultraviolet-visible spectrophotometry.

To date, a special high-temperature burner has been installed in the flame photometer, and a modulator circuit has been assembled to permit atomic absorption as well as emission measurements. Direct injection of a solution of Venezuelan crude oil into the flame has already been shown to produce a strong vanadium emission signal. In other tests, solvents are being evaluated both with respect to their ability to dissolve completely the components of the crude oil as well as to provide suitable behavior in flame analyses. For example, chloroform is a good solvent for the crude oil, but it. quickly forms a deposit on the burner, presumably due to deposition of part of the sample, due to its high volatility. Once all of the common solvents have been evaluated, the most suitable compromise(s) will be selected for detailed chromatographic examination .

Meanwhile, other work is also preceeding along two parallel paths. First, some of the class separations (alkyl vs aromatic) of the porphyrins (7) have been started so as 
to obtain samples suitable for high resolution chromatography. A second set of studies is being directed toward the exploration of conditions in supercritical fluid chromatography and high resolution liquid chromatography that will not only provide good recoveries for vanadium but also permit high-sensitivity flame analyses to be run directly on the eluent. Although demetallation during isolation has been suspected by earlier workers using conventional liquid-liquid extraction or liquid chromatography, it will not be a primary concern until we leam how to handle the more stable vanadium species.

The final topic in this section of the proposal, analyses of copolymers, represents a very challenging problem that is widely encountered in industry. However, no student elected to start that study.

Subcritical temperature or pressure. Three of the four topics proposed in this section last year have been started-and two of them have been completed. First, recycling chromatography has been shown in our laboratory (9) and, independently, in a Russian laboratory (10) to be a much more powerful technique when operated at an elevated pressure. Plate numbers, corresponding to those obtainable in capillary columns, and sample sizes, characteristic of packed columns, can be combined for difficult separations of two-component or three-component mixtures, such as those of optical isomers or isotopic species. Earlier studies indicated that higher pressures (using a valve at the exit end of the column to maintain the pressure) combined with coarser particles (to minimize the pressure drop) permitted significant improvements to be made.

New pressure controllers and transducers have been received as have the special, ' coarse packing materials. As soon as the system has been tested using a single compound (to observe the peak-spreading as a function of the number of cycles), a difficult separation, such as that of the isotopic species in carbon dioxide, will be used to test the system performance. 
For a number of years, the effects of pressure (up to $60,000 \mathrm{psi}$ ) on retention times observed in different types of liquid chromatographic processes have been studied in our laboratory. During the early part of the contract period, the effect of pressure on the cation exchange behavior of alkaline metal ions was written up (11). In addition, the effects of pressure on the retention of ion-pairs was completed (12) as was the effect of temperature. Unlike an earlier report on ion pairing (13), the temperature effect on an ion pair formed by an anionic dye, such as methyl red, and a cation, such as tetrahexylammonium ion, was found in reverse-phase chromatography to behave in a very conventlonal fashion. That is to say, retention decreased in a regular fashion with increasing temperature. Hence, the ion pairs in question could not be distinguished on that basis from conventional liquid-liquid partitioning of the dye alone. In addition, the behavior was much the same when the ion pair was extracted into a bulk liquid layer of $n$-octadecane and when it was "extracted" by a silica-bonded layer of octadecyl groups.

High-Temperature Solubility Studies (Relating to Geothermal Brines)

The goal of this study is to determine the solubility (and especially the changes in solubility with temperature and pressure) of one or more inorganic species that often precipitate from geothermal brines. The two species in which we are most interested are silica and basic iron chloride. Silica represents a species that is wide spread and, although a minor constituent, it has a very limited solubility, especially in acidic solutions. Likewise, although chloride is often found in very large concentrations, iron has usually been reported to be very dilute, 1,000 parts per million or less. Nevertheless, both silica and basic iron chloride tend to precipitate out in the form of a scale (14). The compounds also share the property of having a solubility that can be greatly affected by a small change in $\mathrm{pH}$. The $\mathrm{pH}$, in turn, is affected by the 
temperature of the brine and the partial pressure of carbon dioxide. Hence, when the temperature and pressure are changed as a result of passage of the brine through heat exchanges, precipitation can occur. Unfortunately, most brines have temperatures less than $300^{\circ} \mathrm{C}$ so that precipitation (and dissolution) kinetics for silica are slow, thereby complicating any equilibrium studies. The same may be true, probably to a lesser extent, for the basic iron chloride. Nevertheless, it should be worthwhile to attempt to obtain equilibrium values for one or both of these systems.

The general approach will be based on the very slow passage of water through a bed of silica held at an appropriate temperature and pressure. By examining different lengths of silica beds and different rates of flow, it should be possible to assess whether or not an equilibrium value has been reached for a given combination of temperature and pressure. For the initial experiment, we plan to use silica in contact with water rather than a simulated brine.

At the present time, no work has been done on this project other than to obtain a suitable pressure gauge. Delivery of the gauge was delayed many months with the result that it arrived only a month before the postdoctoral associate left the laboratory. Hopefully, work can be started during the next year.

\section{Other Studies}

Volatility behaviors of metal chelates. As indicated earlier, one of the goals in our study of the volatility of vanadium chelates in Venezuelan crude oil is to identify as accurately as possible each of the volatile species. On the assumption that a species can be isolated using either liquid chromatography or supercritical fluid chromatography, mass spectrometry would be very useful for the identification. To that end, we have designed a special heated inlet that is based upon a highly reproducible pyrolysis unit. We have demonstrated that the special sample probe system works well by using a sample 
of thallium (I) diethyldithiocarbamate. The same peaks were found, including those for the molecular ions, but the abundance represented by the latter was twice as large as when the conventional high-temperature probe was used. Hence, as soon as a vanadium chelate has been isolated, it should be possible to obtain a good mass spectrum.

Shortly after the above tests had been completed on the thallium chelate, some exploratory runs were made using cysteine and glycine complexes of zinc. No evidence was found for the formation of a molecular ion, so further work was discontinued.

Optimization in chromatography. A new graduate student has recently indicated an interest in studying this topic. A recent paper on the information content of an analytical method (15) and its references have been examined. Computer simulations will be made relating to chromatographic separations after assigning values to different parameters of the data. Changes in the overall value of a set of results with deliberate changes in the individual components within a set will be explored.

New column packings for chromatography. New column packings for liquid chromatography are being introduced by a number of manufacturers. During the past year, Lichrosphere, a preparation of small spherical particles of silica having a closely controlled range of pore size, was evaluated for steric exclusion chromatography because it appeared to be more suitable than organic polymer packings for operation at elevated temperatures.

When preliminary studies demonstrated that it was capable of performing high resolution fractionations of monodisperse polystyrene samples in a relatively short time, some molecular-weight distributions of Venezuelan crude oils, of asphaltene fractions from those crudes, and of some coal tars and petroleum pitches were examined. It was possible to perform separations in approximately 30 minutes that usually took four hours or longer (16). As a result, this packing should be quite useful for any future work on characterizing large molecular weight species in petroleum and liquified coal. 
Liquid chromatographic fractionation of polystyrene. As indicated earlier, separations of monodisperse polystyrene samples using supercritical fluid chromatography showed not only many peaks for oligomers but also a large unresolved hump. For that reason, it appeared desirable to explore the separation using another technique. Just as we were about to start our work, advertising brochures from Perkin-Elmer and Waters Associates were published showing single chromatograms, each obtained under different conditions, that confirmed the promise of gradient-solvent liquid-chromatographic procedures for polymer fractionations.

Although approximately 25 oligomer peaks were obtained using different polar solvents with hexane, the unresolved envelope beneath them changed with the binary solvent combination and $\mathrm{its}$ concentration gradient. That behavior suggested three possibilities for explaining the envelope of unresolved species. First, one or more impurities might be present. Second, another series of unresolved oligomers might be present. Third, some polystyrene first adsorbed on the surface of the column packing and then the rest of the sample partitioned into that layer; when the layer slowly desorbed, it gave unresolved components. There is evidence for both the first and third possibilities; the second has not been ruled out. An increased level of effort is now being devoted to this study.

Nitrogen detector-synthesis of special beads. During the past year, a new design of a detector, that permits very sensitive quantitation of nitrogen in organic compounds was obtained. When used in parallel with the spectrophotometric vanadium determination, it should permit immediate confirmation of the presence of nitrogen in the chelate. Furthermore, it can provide evidence for nitrogen compounds that do not contain vanadium but might represent demetallized species.

Although the detector is very sensitive, the glass beads used as its active element burn out rather quickly with heavy use. Not only are they very expensive but deliveries 
have been slow. For that reason, a brief empirical study of the synthesis of glass beads, starting with the vague description of the composition as stated in the patent (17) was undertaken. A number of bead compositions were characterized for sensitivity, selectivity and stability.

It turned out that satisfactory beads can be made quickly and cheaply (SRO-854-16). A by-product of the study was the finding that the proposed mechanism by which the detection is supposed to occur can not be correct. However, the overall mechanism is very complex and, because our interest in the mechanism was secondary to the use of the bead, those studies have not heen pursued further.

\section{GENERAL REMARKS}

Much of our effort each year goes into the design and building of electronic circuits ranging from signal conditioners to interfaces either for control of new chromatographic components or for improved control of existing components. Similarly, computer programs for data acquisition, control of equipment, and analysis of data are undergoing constant change. Although our existing minicomputer system reached the saturation point long ago, we continue to increase the number of instruments to which it can be attached. Even though only two or three experiments can be on-line at any one time, the best possible data can be obtained from each piece of equipment. Close scheduling and good teamwork has been the key to the success of this approach. 


\section{REFERENCES}

1. R. B. Westerberg, F. J. Van Lenten and L. B. Rogers, Separ. Sci., 10, 593 (1975).

2. R. E. Pauls and L. B. Rogers, Anal. Chem., 49, 625 (1977).

3. A. T. Shepard, N. D. Danielson, R. E. Pauls, N. H. Mahle, P. J. Taylor and L. B. Rogers, Separ. Sci., 11, 279 (1976).

4. R. H. Betts and W. D. Buchannon, Can. J. Chem., 54, 3007 (1976).

5. R. E. Jentoft and T. H. Gouw, J. Chromatogr. Sci., 8, 138 (1970).

6. J. A. Nieman and L. B. Rogers, Separ. Sci., 10, 517 (1975).

7. M. Nuzzi and A. Casalini, Revista dei Combustibile, 28(2), 49 (1974).

8. E. W. Baker, T. F. Yen, J. P. Dickie, R. P. Rhodes and L. F. Clark, J. Am. Chem. Soc., 89, 3631 (1967); see also E. W. Baker, J. Am. Chem. Soc., 88, 2311 (1966).

9. R. E. Pauls, A. T. Shepard, J. E. Phelps, J. E. Davis and L. B. Rogers, Separ. Sci., 12(3), 289 (1977).

10. V. P. Chizhkov, G. A. Yushina, L. A. Sinitzina and B. A. Rudenko, J. Chromatogr., 120, 35 (1976).

11. G. Prukop and L. B. Rogers, SRO-854-13, Accepted by Separation Science.

12. G. Prukop and L. B. Rogers, SRO-854-14, Accepted by Separation Science.

13. J. C. Kraak and J. F. K. Huber, J. Chromatogr., 102, 333 (1974).

14. R. Lim, Lawrence Livermore Laboratory, Private communications, 1974 and 1976.

15. K. Eckschlager, Anal. Chem., 49, 1265 (1977).

16. J. C. Hodgin, M. A. Kaiser, J. A. Lubkowitz and L. B. Rogers, J. Chromatogr., 135,514 (1977).

17. B. Kolb and j. Bischoff, U. S. Patent 3852037 (1974); Idem, J. Chromatogr. Sci., 12,625 (1974). 


\section{PUBLICATIONS AND REPORTS}

SRO-854-6 Frank J. Van Lenten, James E. Conaway, and L. B. Rogers Gas Chromatographic Retention Characteristics of Different Polysiloxane Oligomers, Separation Science, 12(1), 1-28, 1977.

SRO-854-7 .R. E. Pauls, N. H. Mahle, A. T. Shepard, Jenny Chow Gaw, and $L$. B. Rogers

Chromatographic Determination of the Relative Retention of Isotopic Species of Oxygen in Methanol and Methan-d ${ }^{3}-o l$, Separation Science, $12(3)$, 307-320, 1977.

SRO-854-8. Gabriel Prukop and L. B. Rogers

An Inexpensive Drop Counter for Use With Fraction Collectors, Chemical Instrumentation, 7(4), 287-293, 1976.

SRO-854-9 R. E. Pauls and L. B. Rogers

Band Broadening Studies Using Parameters for an Exponentially Modified Gaussian, Analytical Chemistry, 49, 625, 1977.

SRO-854-10 R. E. Pauls and L. B. Rogers

Comparisons of Methods for Calculating Retention and Separation of Chromatographic Peaks, Separation Seience, 12(4), 395-413, 1977.

SRO-854-12 J. C. Hodgin, M. A. Kaiser, J. A. Lubkowitz, and L. B. Rogers Rapid Method for Characterization of Heavy Petroleum Fractions, Journal of Chromatography, 135, 514-520, 1977.

SRO-854-13 Gabrlel Prukop and L. B. Rogers

Cation Exchange at Pressures Up to $400 \mathrm{M}$ Pascals, Accepted by Separation Science.

SRO-854-14 Gabriel Prukop and L. B. Rogers Reverse Phase lon-Pairing Chromatography at Pressures up to $345 \mathrm{MPa}$, Accepted by Separation Science.

SRO-854-15 J. A. Lubkowitz, B. P. Semonian, Javier Galobardes and L. B. Rogers Preparation and Characterization of Glass Beads for Use in Thermionic Gas Chromatographic Detectors, Submitted to Analytical Chemistry.

SRO-854-16 J. E. Conaway and L. B. Rogers

Effects on Gas Chromatographic Peaks of Electric Fields Applied Across Cholesteric Liquid Crystal Stationary Phases, Accepted by Separation Science.

SRO-854-17 B. P. Semonian, J. A. Lubkowitz and L. B. Rogers

Positive Pressure Columns Used for Solvent Cleanup or Chromatography, Submitted to Analytical Chemistry. 


\section{PERSONNEL}

September 1976 through August 1977

Graduate Students

James Conaway

John Fetzer

Javier Galobardes

Joseph Glajch

Jeffrey Graham

John Hodgin (Terminated October 1976)

Charles Potter

Gabriel Prukop (Terminated May 1977)

Bruce Semonian

William Spencer

Postdoctoral Associates

Dr. V. O. Brandt (Terminated June 1977)

Professor J. A. Lubkowitz, part-time (Terminated April 1977)

Professor J. F. Parcher, part-time (Terminated May 1977)

Dr. J. W. Webb 